NASZA DERMATOLOGIA Online OUR DERMATOLOGY Online

Source of Support: Nil

Competing Interests: None

\section{PSORIASIS UNCOVERED - COMORBID CONDITIONS WITH SPECIAL REFERENCE TO METABOLIC SYNDROME}

\author{
Belliappa Pemmanda Raju, Umashankar Nagaraju
}

Department of Dermatology, Rajarajeswari Medical College and Hospital, Kambipura, Kengeri Hobli, Mysore Road, Bangalore - 560074, Karnataka, India

Corresponding author: Prof. Belliappa Pemmanda Raju마belliappa@gmail.com

\begin{abstract}
Introduction: Psoriasis is a chronic immune-inflammatory-mediated disease affecting approximately 1-3\% of the population worldwide. All around the world, there is growing evidence of the association between psoriasis and comorbidities, especially metabolic syndrome which increases the risk of cardiovascular disease. Co-morbidities are likely linked to underlying chronic inflammatory nature of psoriasis.

Aim: The objectives of our study were to determine the prevalence of diabetes, lipid abnormalities, and cardiovascular risk factors in patients with plaque psoriasis, and also to investigate metabolic syndrome associated with plaque psoriasis.

Material and Methods: One hundred and twenty patients with psoriasis vulgaris diagnosed clinically and histopathologically were recruited. A detailed history and examination was recorded for all study subjects, including the age and gender of the patients, extent of psoriasis, duration, and age at onset. Metabolic syndrome was diagnosed in the presence of three or more criteria of abdominal obesity, blood pressure $>130 / 85 \mathrm{mmHg}$, fasting blood glucose $\geq 100 \mathrm{mg} / \mathrm{dl}$, hypertriglyceridemia $>150 \mathrm{mg} / \mathrm{dl}$, and low HDL cholesterol ( $<40 \mathrm{mg} / \mathrm{dl}$ for males, $<50 \mathrm{mg}$ / dl for females).

Results: Prevalence of various comorbidities was: central obesity (58.3\%), hypertension (46.79\%), dyslipidaemia (43.3\%), diabetes mellitus (26.7\%), metabolic syndrome (25\%), ischaemic heart disease (5\%) and stroke (2.4\%). Prevalence of metabolic syndrome was more in patients who had longer mean disease duration of psoriasis.

Conclusions: The perception of psoriasis being merely 'skin deep' has to change among clinicians. Active screening for these cardiovascular comorbidities in all psoriasis patients is highly recommended.
\end{abstract}

Key words: psoriasis vulgaris; comorbidities; metabolic syndrome

\section{Introduction}

Psoriasis is a chronic immune-inflammatory-mediated disease affecting approximately $1-3 \%$ of the general population $[1,2]$. Psoriasis is not just a disease of skin and joints, but is a systemic disease that is connected with a range of comorbiditiesespecially metabolic syndrome and cardiovascular disease. Comorbid conditions linked with psoriasis are associated with increasing rates of morbidity and mortality [3]. Metabolic syndrome is a cluster of risk factors including central obesity, atherogenic dyslipidaemia, hypertension and glucose intolerance. It is a strong predictor of cardiovascular diseases, diabetes and stroke [4]. Similarities exist among psoriasis, metabolic syndrome and atherosclerosis, with all three conditions characterized by an inflammatory process driven by Th1 cytokines [5,6]. Increasing population-based studies have suggested a relationship between psoriasis and metabolic syndrome [7]. Purpose of our study was to determine the prevalence of comorbidities in patients with psoriasis vulgaris, with special emphasis on metabolic syndrome, as it remains largely unelucidated in the Indian population.

\section{Material and Methods}

Prospective, observational hospital based study. One hundred and twenty patients with psoriasis vulgaris diagnosed clinically and histopathologically were included in this study which was carried out of our Department of Dermatology from March 2011 to August 2012 for a period of 18 months. Patients with plaque-type psoriasis aged above 18 years were included in the study. Patients receiving systemic treatment for their psoriasis in the last one month were excluded. Informed consent was taken from patients who were enrolled. Information sheets for the patients included age, gender, weight, height, body mass index (BMI), waist circumference, smoking habits, blood pressure, age of onset, and duration of the disease. 
Severity of psoriasis was assessed by percent body surface area (\%BSA) and psoriasis area severity index (PASI). BSA is calculated using the "rule of nines". BSA is the arithmetic mean of the affected skin surface based on the assumption that the head $(\mathrm{H})$ presents $10 \%$, the upper extremities (U) $20 \%$, the trunk (T) $30 \%$, and the lower extremities (L) $40 \%$ of the total body surface [8]. PASI is a composite score from 0 to 72. PASI assesses the degree of erythema (E), infiltration (I), and desquamation (D) in the above-mentioned sites (H, U, T, L) [9]. These features are appraised in these sites using a fourpoint scale: 0: no symptoms; 1: slight symptoms; 2 : moderate symptoms; 3: marked symptoms; 4: very marked symptoms. The scores used to describe the coverage of skin disease in the distinct areas are: 0 : $0 \% ; 1:<10 \% ; 2: 10-29 \% ; 3: 30-49 \% ; 4$ : 50-69\%; 5: 70-89\%; 6: 90-100\%. Therefore, PASI takes both coverage $(\mathrm{A})$ and severity $(\mathrm{E}, \mathrm{I}$ and $\mathrm{D})$ into consideration. It is calculated by:

$\mathrm{PASI}=0.1 *(\mathrm{EH}+\mathrm{IH}+\mathrm{DH}) \mathrm{AH}+0.2 *(\mathrm{EU}+\mathrm{IU}+\mathrm{DU}) \mathrm{AU}+$ $0.3 *(\mathrm{ET}+\mathrm{IT}+\mathrm{DT}) \mathrm{AT}+0.4 *(\mathrm{EL}+\mathrm{IL}+\mathrm{DL}) \mathrm{AL}$

It was classified as moderate to severe in patients with PASI > 10 , and mild in patients with PASI $\leq 10$. BMI was calculated as weight/height $\left(\mathrm{kg} / \mathrm{m}^{2}\right)$. Metabolic syndrome was diagnosed using the South Asian Modified National Cholesterol Education Program Adult Treatment Panel III criteria (SAM-NCEP criteria) [10]. If three or more of the following were present, the patient was diagnosed as having metabolic syndrome: abdominal obesity (definition of abdominal obesity was modified using Asia Pacific WHO guidelines as waist circumference $\geq 90 \mathrm{~cm}$ for males and $\geq 80 \mathrm{~cm}$ for females), blood pressure $>130 / 85 \mathrm{mmHg}$, fasting blood glucose $\geq 100 \mathrm{mg} / \mathrm{dl}$, hypertriglyceridemia $>150$ $\mathrm{mg} / \mathrm{dl}$, or low HDL cholesterol $(<40 \mathrm{mg} / \mathrm{dl}$ for males and $<50$ $\mathrm{mg} / \mathrm{dl}$ for females). ECG was done in all patients and angiogram wherever required. Statistical comparisons were performed using the Student's t- test. The data were considered statistically significant if $\mathrm{p}$ values were less than $0.05(\mathrm{p}<0.05)$.

\section{Results}

The study group included 120 patients, with $86(71.7 \%)$ males and $34(28.3 \%)$ females with a male to female ratio of 2.53:1. Age of the patients ranged from 18 years to 62 years with a mean age of 37.34 years. Duration of the disease ranged

\begin{tabular}{|l|l|}
\hline \multicolumn{1}{|c|}{ Comorbidities } & \multicolumn{1}{c|}{ Number (\%) } \\
\hline Central obesity & $70(58.3 \%)$ \\
\hline Hypertension & $56(46.7 \%)$ \\
\hline Dyslipidemia & $52(43.3 \%)$ \\
\hline Diabetes Mellitus & $32(26.7 \%)$ \\
\hline Metabolic Syndrome & $30(25 \%)$ \\
\hline Ischaemic Heart Disease (IHD) & $6(5 \%)$ \\
\hline Stroke & $3(2.4 \%)$ \\
\hline
\end{tabular}

Table I. Prevalence of different comorbidities in psoriasis from 2 months to 30 years, with a mean duration of 6.67 years. Mean age at onset was 31.41 years, with minimum age 12 years and maximum age 60 years at onset. Severity of psoriasis was moderate to severe in $68(56.7 \%)$ of the patients and mild in $52(43.3 \%)$ of the patients with a Median PASI of 13.05 . PASI score ranged from 5 to 70 . BSA involved ranged from $6 \%$ to $80 \%$, with a Median BSA of $20 \%$.

Central obesity was the most prevalent comorbidity, affecting $70(58.3 \%)$ patients with psoriasis, followed by hypertension, dyslipidaemia, diabetes mellitus, metabolic syndrome, ischaemic heart disease and stroke (Tabl. I). Waist circumference $\geq 90 \mathrm{~cm}$ in men and $\geq 80 \mathrm{~cm}$ in women was observed in $42(35 \%)$ and 28 $(23.3 \%)$ patients respectively. Obesity measured by BMI was present in $64(53.3 \%)$ patients. Metabolic syndrome was seen in $30(25 \%)$ patients of psoriasis. Distribution of risk factors and different components of Metabolic Syndrome are given in Table II.

On analyzing psoriatic patients with and without metabolic syndrome, we found that patients with metabolic syndrome had longer mean disease duration than psoriatic patients without metabolic syndrome, which was significant. There was no significant difference regarding psoriasis severity, gender or prevalance of smoking between psoriatic patients with and without metabolic syndrome (Tabl III). Metabolic syndrome in psoriasis was seen more commonly in the patients aged above sixty years, however we also observed early onset of metabolic syndrome in psoriasis (Tabl. IV).

\section{Discussion}

Recent studies on western population show that psoriasis is associated with metabolic disorders such as hypertension, type II diabetes mellitus, dyslipidemia, abdominal obesity, insulin resistance, and cardiac disorders and the risk of metabolic syndrome is increased in patients with psoriasis [11-19]. Metaanalysis of studies has shown that psoriatics had increased odds (two-fold) of developing metabolic syndrome compared with the general population.

Metabolic syndrome has a high prevalence among psoriasis. Possible biologic mechanisms for this may be due to: chronically elevated free fatty acid (FFA) levels which lead to adipocyte dysfunction which in turn inhibit insulin secretion and up-regulation of proinflammatory adipokines like adiponectin, leptin, resistin and visfatin [7].

\begin{tabular}{|l|l|}
\hline \multicolumn{1}{|c|}{$\begin{array}{c}\text { Risk factors/Components of } \\
\text { Metabolic Syndrome }\end{array}$} & \multicolumn{1}{c|}{ Number (\%) } \\
\hline Smokers & $18(15 \%)$ \\
\hline Alcoholic & $46(38.3 \%)$ \\
\hline $\begin{array}{l}\text { Waist circumference: } \\
\text { Male } \\
\text { Female }\end{array}$ & $42(35 \%)$ \\
& $28(23.3 \%)$ \\
\hline Hypertension & $56(46.7 \%)$ \\
\hline Hypertriglyceridemia & $52(43.3 \%)$ \\
\hline Low Level HDL & $40(33.3 \%)$ \\
\hline Diabetes Mellitus (FBS $>100 \mathrm{mg} / \mathrm{dl})$ & $32(26.7 \%)$ \\
\hline
\end{tabular}

Table II. Distribution of risk factors and components of Metabolic Syndrome. 


\begin{tabular}{|l|l|l|l|}
\hline \multicolumn{1}{|c|}{ Characteristic } & \multicolumn{1}{|c|}{ With MS (n=30) } & \multicolumn{1}{c|}{ Without MS (n=90) } & \multicolumn{1}{c|}{ t-test } \\
\hline Sex $(\mathrm{M} / \mathrm{F})$ & $21 / 9$ & $65 / 25$ & NS \\
\hline Disease duration & $13.67 \pm 11.87$ & $6.46 \pm 5.80$ & $(\mathrm{P}<0.0005)$ \\
\hline Smoker & 6 & 12 & NS \\
\hline PASI $>10$ & 21 & 47 & NS \\
\hline BSA $>10 \%$ & 23 & 55 & NS \\
\hline Mean PASI & $14.30 \pm 12.37$ & $16.77 \pm 14.53$ & NS \\
\hline Mean BSA & $25.80 \pm 21.17$ & $27.55 \pm 25.7$ & NS \\
\hline
\end{tabular}

Table III. Descriptive features of psoriatic patients with and without Metabolic Syndrome (MS).

NS=Not significant

\begin{tabular}{|l|l|l|l|l|}
\hline \multicolumn{1}{|c|}{ Comorbidities (\%) } & \multicolumn{1}{|c|}{ Nisa et al } & \multicolumn{1}{c|}{ Khunger et al } & Madanagobalane et al & \multicolumn{1}{c|}{ Present study } \\
\hline Smoking & $42 \%$ & - & $16.1 \%$ & $15 \%$ \\
\hline Hypertriglyeridemia & $48.6 \%$ & $16 \%$ & $33.9 \%$ & $43.3 \%$ \\
\hline Hypertension & $49.3 \%$ & $26 \%$ & $30.5 \%$ & $46.7 \%$ \\
\hline Low HDL levels & $56.6 \%$ & - & $36.4 \%$ & $33.3 \%$ \\
\hline Obesity & $14.6 \%$ & $38 \%$ & $34.7 \%$ & $58.3 \%$ \\
\hline Diabetes Mellitus & $18 \%$ & $16 \%$ & $61 \%$ & $26.7 \%$ \\
\hline
\end{tabular}

Table IV. Comparision of prevalence of metabolic syndrome components in different Indian studies.

Studies on the Indian population with relation to psoriasis and its comorbidities and metabolic syndrome are limited. The prevalence of metabolic syndrome in psoriasis was $25 \%$ in our study, which is consistent with other Indian studies, which have shown a prevalence ranging from $18.2 \%-44.1 \%[4,20-23]$. This wide variation in the prevalence of metabolic syndrome could be due to ethnic, dietary and lifestyle changes in different parts of the country. Prevalence of different metabolic syndrome components in our study is compared with other Indian studies in Table V. Association with smoking was seen in $15 \%$ of our patients which is consistent with a study by Madanagobalane et al [20]. Association with smoking may be partly explained by the action of nicotine in promoting Th1 mediated inflammation [6]. Smoking induces an overproduction of IL-1 $\beta$, TNF- $\alpha$ and TGF- $\beta$, which have been associated with psoriasis severity [24]. In our study $38.3 \%$ of patients were alcoholic, other Indian studies have reported an association of $9.1 \%$ to $17.7 \%[20,23]$. Alcoholism has been related with psoriasis, and studies have reported 1.3-1.6 fold increased risk in development of psoriasis in alcoholics [25]. Hypertriglyceridemia and low HDL levels were seen in $43.3 \%$ and $33.3 \%$ of our patients which is consistent with a study by Madanagobalane et al [20].
Pro-inflammatory cytokines TNF- $\alpha$ and IL-6 over expressed in psoriasis contributes to dyslipidaemia [26]. Obesity was observed in $58.3 \%$ of our patients which is much higher than other Indian studies which have reported an association of $14.6 \%$ to $38 \%$ [21,22].

Leptin produced by adipose tissue and increased TNF- $\alpha$ acts as a potential link between obesity and psoriasis [27,28]. Diabetes mellitus was seen in $26.7 \%$ of our patients, while other Indian studies have reported a prevalence ranging from $16 \%$ to $61 \%[20,22]$. Chronically elevated FFA levels inhibit insulin secretion, and TNF- $\alpha$ and IL- 6 contributes to insulin resistance $[7,26]$. Fifty six $(46.7 \%)$ patients were hypertensive in our study which is consistent with another Indian study by Nisa et al.[21]. Henselar et al in 40,000 dermatological patients found 1.9 fold greater likelihood of hypertension in psoriatics compared to other dermatological conditions [11].

Our study showed a significant relationship between duration of psoriasis and metabolic syndrome, which is consistent with a study by Nisa et al.[21].

There was no significant relationship between psoriasis severity and metabolic syndrome in our study, which is consistent with other Indian studies [20,21].

\begin{tabular}{|l|l|}
\hline \multicolumn{1}{|c|}{ Age Group } & \multicolumn{1}{c|}{$\%$} \\
\hline $18-30$ Yrs & $12.9 \%$ \\
\hline $31-40$ Yrs & $29.7 \%$ \\
\hline $41-50$ Yrs & $44.4 \%$ \\
\hline $51-60$ Yrs & $37.5 \%$ \\
\hline$>60$ Yrs & $50 \%$ \\
\hline
\end{tabular}

Table V. Prevalance of Metabolic Syndrome among different age groups. 
However, Langan et al found a robust dose-response relationship between psoriasis severity and prevalence of metabolic syndrome [29]. This observation was supported by the translational data that T- helper inflammatory cytokines are increased in skin and sera of psoriatic patients and these exert systemic effects on insulin regulation and lipid metabolism [30]. Onset of metabolic syndrome in psoriasis was seen at a younger age in our study which is consistent with a study reported by Nisa et al.[21]. Relative risk of cardiovascular mortality is highest in younger patients less than forty years, with severe psoriasis [15]. So early therapeutic intervention would diminish the risk of cardiovascular disease and mortality in psoriasis. Our results showed that psoriasis predisposes to the development of a distinct cluster of concomitant diseases, including hypertension, dyslipidemia, obesity and metabolic syndrome. Hence all patients with psoriasis should be monitored for associated co-morbid conditions. For effective management of psoriasis and related co-morbidities, an integrated approach targeting both cutaneous and systemic manifestations may be beneficial.

Limitation of this study was that the sample size was not large enough to represent the general population. Further large prospective, randomized, controlled, population-based studies should be undertaken to confirm the association and causality between psoriasis and metabolic syndrome.

\section{Conclusion}

Approach psoriasis as a potentially multisystem disorder and alert patients to the potentially negative effects of psoriasis as it relates to other aspects of their health.

Can we now consider psoriasis as a cutaneous marker for metabolic syndrome?

\section{REFERENCES}

1. Gelfand JM, Weinstein R, Porter SB, Neimann AL, Berlin JA, Margolis DJ. Prevalence and treatment of psoriasis in the United Kingdom: a population-based study. Arch Dermatol. 2005;141:153741.

2. Kurd SK, Gelfand JM. The prevalence of previously diagnosed and undiagnosed psoriasis in US adults: results from NHANES 20032004. J Am Acad Dermatol. 2009;60:218-24.

3. Christophers E. Comorbidities in psoriasis. J Eur Acad Dermatol Venerol. 2006; 20:52-5.

4. Malhotra SK, Dhaliwal GS, Puri KJPS, Gambhir ML, Mahajan M. An insight into relationship between psoriasis and metabolic syndrome. Egypt Dermatol Online J. 2011;7:5.

5. International Psoriasis Council. Obesity in psoriasis: the metabolic, clinical and therapeutic implications. Report of an interdisciplinary conference and review. Br J Dermatol. 2007;157:649-55.

6. Kremers HM, McEvoy MT, Dann FJ, Gabriel SE. Heart disease in psoriasis. J Am Acad Dermatol. 2007;57:347-54.

7. Armstrong AW, Harskamp CT, Armstrong EJ. Psoriasis and metabolic syndrome: a systematic review and meta-analysis of observational studies. J Am Acad Dermatol. 2013;68:654-62.

8. Wallace AB. The exposure treatment of burns. Lancet. 1951;3:5014.

9. Fredriksson T, Pettersson U. Severe psoriasis - oral therapy with a new retinoid. Dermatologica. 1978;157:238-44.

10. Enas EA, Mohan V, Deepa M, Farooq S, Pazhoor S, Chennikkara $\mathrm{H}$. The metabolic syndrome and dyslipidemia among Asian Indians:
A population with high rates of diabetes and premature coronary artery disease. J Cardiometab Syndr. 2007;2:267-75.

11. Henseler T, Christophers E. Disease concomitance in psoriasis. J Am Acad Dermatol. 1995;32:982-6.

12. Sommer DM, Jenisch S, Suchan M, Christophers E, Weichenthal M. Increased prevalence of the metabolic syndrome in patients with moderate to severe psoriasis. Arch Dermatol Res. 2006;298:321-8.

13. Mallbris L, Ritchlin CT, Stahle M. Metabolic disorders in patients with psoriasis and psoriatic arthritis. Curr Rheumatol Rep. 2006;8:355-63.

14. Mallbris L, Akre O, Granath F, Yin L, Lindelöf B, Ekbom A, Ståhle-Bäckdahl M. Increased risk for cardiovascular mortality in psoriasis inpatients but not in outpatients. Eur J Epidemiol. 2004;193:225-30.

15. Gelfand JM, Neimann AL, Shin DB, Wang X, Margolis DJ, Troxel AB. Risk of myocardial infarction in patients with psoriasis. JAMA. 2006;296:1735-41.

16. Christophers E. Comorbidities in psoriasis. Clin Dermatol. 2007;25:529-34.

17. Wakkee M, Thio HB, Prens EP, Sijbrands EJ, Neumann HA. Unfavorable cardiovascular risk profiles in untreated and treated psoriasis patients. Atherosclerosis. 2007;190:1-9.

18. Malerba M, Gisondi P, Radaeli A, Sala R, Calzavara Pinton PG, Girolomoni G. Plasma homocysteine and folate levels in patients with chronic plaque psoriasis. Br J Dermatol. 2006;155:1165-9.

19. Shapiro J, Cohen AD, David M, Hodak E, Chodik G, Viner A, et al. The association between psoriasis, diabetes mellitus, and atherosclerosis in Israel: a case-control study. J Am Acad Dermatol. 2007;56:629-34.

20. Madanagobalane S, Anandan S. Prevalence of metabolic syndrome in South Indian patients with psoriasis vulgaris and the relation between disease severity and metabolic syndrome: a hospital-based case-control study. Indian J Dermatol. 2012;57:353-7. 21. Nisa N, Qazi MA. Prevalence of metabolic syndrome in patients with psoriasis. Indian J Dermatol Venereol Leprol. 2010;76:662-5.

22. Khunger N, Gupta D, Ramesh V. Is psoriasis a new cutaneous marker for metabolic syndrome? A study in Indian patients. Indian J Dermatol. 2013;58:313-4.

23. Pereira RR, Amladi ST, Varthakavi PK. A study of the prevalence of diabetes, insulin resistance, lipid abnormalities, and cardiovascular risk factors in patients with chronic plaque psoriasis. Indian $\mathrm{J}$ Dermatol. 2011;56:520-6.

24. Al-Mutairi N, Al-Farag S, Al-Mutairi A, Al-Shiltawy M. Comorbidities associated with psoriasis: an experience from the Middle East. J Dermatol. 2010;37:146-55.

25. Naldi L, Parazzini F, Brevi A, Peserico A, Veller Fornasa C, Grosso G, et al. Family history, smoking habits, alcohol consumption and risk of psoriasis. Br J Dermatol. 1992;127:212-7.

26. Sommer DM, Jenisch S, Suchan M, Christophers E, Weichenthal M. Increased prevalence of the metabolic syndrome in patients with moderate to severe psoriasis. Arch Dermatol Res. 2006;298:321-8.

27. Prey S, Paul C, Bronsard V, Puzenat E, Gourraud PA, Aractingi $\mathrm{S}$, et al. Cardiovascular risk factors in patients with plaque psoriasis: a systematic review of epidemiological studies. J Eur Acad Dermatol Venereol. 2010;24Suppl 2:23-30.

28. Kimhi O, Caspi D, Bornstein NM, Maharshak N, Gur A, Arbel Y, et al. Prevalence and risk factors of atherosclerosis in patients with psoriatic arthritis. Semin Arthritis Rheum. 2007;36:203-9.

29. Langan SM, Seminara NM, Shin DB, Troxel AB, Kimmel SE, Mehta NN, et al. Prevalence of metabolic syndrome in patients with psoriasis: a population-based study in the United Kingdom. J Invest Dermatol. 2012;132:556-62.

30. Azfar RS, Gelfand JM. Psoriasis and metabolic disease: epidemiology and pathophysiology. Curr Opin Rheumatol. 2008;20:416-22.

Copyright by Belliappa Pemmanda Raju, et al. This is an open access article distributed under the terms of the Creative Commons Attribution License, which permits unrestricted use, distribution, and reproduction in any medium, provided the original author and source are credited. 